\title{
Treatment Pattern and Factors Associated with Blood Pressure and Fasting Plasma Glucose Control among Patients with Type 2 Diabetes Mellitus in Police Referral Hospital in Ethiopia
}

\author{
Tariku Shimels $^{1 *}$, Melesse Abebaw ${ }^{2}$, Arebu I. Bilal $^{3}$, Tariku Tesfaye ${ }^{4}$
}

OPEN ACCESS

Citation: Shimels Tariku, Abebaw Melesse, Bilal I. Arebu, Tesfaye Tariku. Treatment Pattern and Factors Associated with Blood Pressure and Fasting Plasma Glucose Control among Patients with Type 2 Diabetes Mellitus in Federal Police Referral Hospital, Ethiopia. Ethiop J Health Sci.2018; 28 (4):461.

doi:http://dx.doi.org/10.4314/ejhs.v28i4.12

Received: February 6, 2018

Accepted: March 28, 2018

Published: July 1, 2018

Copyright: (C) 2018 Shimels Tariku, et al. This is an open access article distributed under the terms of the Creative Commons Attribution License, which permits unrestricted use, distribution, and reproduction in any medium, provided the original author and source are credited.

Funding: Nil

Competing Interests: The authors declare that this manuscript was approved by all authors in its form and that no competing interest exists.

Affiliation and Correspondence:

${ }^{1}$ Medical Logistics and Pharmacy

Service Coordination, Ethiopian

Federal Police Commission Health

Service Directorate, Ethiopia

${ }^{2}$ Federal Police Referral Hospital, Addis Ababa, Ethiopia

${ }^{3}$ Department of Pharmaceutics and Social Pharmacy, School of Pharmacy, College of Health Sciences, Addis Ababa University

${ }^{4}$ Police Health Professionals Training Institute, Ethiopian Police University College, Ethiopia

*Email: tarphar2008@gmail.com

\section{ABSTRACT}

BACKGROUND: The prevalence of T2DM in Ethiopia is on the rise according to certain studies. Appropriate management approaches are required to achieve desired goals of therapy in the clinical setup. This study was conducted to assess the treatment pattern and the factors associated with BP and FPG control among patients with T2DM in Federal Police Referral Hospital.

METHOD: An institution based cross sectional study was conducted from $15^{\text {th }}$ October 2016 to $15^{\text {th }}$ January 2017. A Systematic random sampling technique was employed in selecting the study participants. Data was collected using semi-structured interview and visiting medication records. SPSS version 20 was used for data analysis.

RESULTS: Out of a total of 414 participants who fulfilled the inclusion criteria, 361 were successfully interviewed and considered for further analysis. Target BP level was achieved in 206(57.1\%) of the patients, whereas the proportion of hypertensive diabetics who attained the recommended BP target was $19.4 \%$ $(n=40)$. Of the 361 participants who were checked about their current FPG level, only 142(39.3\%) were found to be $<130 \mathrm{mg} / \mathrm{dl}$. However, 87(24.1\%) participants were found to control both BP and FPG levels. Gender, military status, comorbidity, type of therapy and dietary adherence showed a statistically significant association with outcome variables.

CONCLUSION: The proportion of participants with T2DM who achieved target BP, FPG or both was suboptimal. A comprehensive approach that involves targeted education on self-management strategies, individualized treatment plans, and continuous evaluation of treatment outcomes should be practiced.

KEYWORDS: Blood pressure, Cross sectional study, Ethiopia, Fasting plasma glucose control, type 2 diabetes mellitus

\section{INTRODUCTION}

Diabetes mellitus (DM) is one of the leading non-communicable diseases affecting a growing number of the population worldwide. A pooled analysis of 751 studies by non-communicable disease (NCD) risk factor collaboration indicated that an estimated 422 million 
adults were living with diabetes in 2014 , compared to 108 million in 1980(1). In this study, the age standardized global prevalence of the disease nearly doubled since 1980, rising from $4.7 \%$ to $8.5 \%$ in the adult population. A report by WHO has also documented that diabetes caused 1.5 million deaths in 2012. And additional 2.2 million deaths were also reported to occur as a result of increased risks of cardiovascular and other diseases. Forty-three percent of these 3.7 million deaths occured before the age of 70 years majority being in low and middle income countires (2).

Even though the burden of diabetes in Ethiopia is not clearly elucidated, there are few studies conducted in selected population groups which show a growing prevalence of the problem (3-6). It is also reported that diabetes is becoming one of the top two causes of admission to hospitals (7). According to a report of the International Diabetes Federation (IDF) in 2014, it was estimated that 4.9 million Ethiopians of the age group 20-79 lived with diabetes and more than 2.9 million $(26.9 \%)$ sufferred from impaired glucose tolerance (8).

There is a direct relationship between development of DM related complications and poor control of glycemic, blood pressure and lipid level targets (2). Studies have reported that improved glycemic control can either delay or prevent the occurrence of micro-vascular complications such as; diabetic retinopathy, nephropathy as well as disorders that would arise secondary to neuropathic attacks (9-10). Nevertheless, the risk of developing macrovascular (cardiovascular) complications is increased among patients with T2DM who have poor lipid, blood pressure, and in particular glycemic control (11).

The American Diabetes Association (ADA) recommends that life style changes are the first line therapy for most individuals. However, the addition of metformin, other oral anti-diabetic drugs (OADs) and/ insulin is also warranted stepwise if the goals are not achieved with life style changes alone $(11,12)$. Even though a national diabetic guideline is not available in Ethiopia to set treatment targets, this study used the blood pressure (BP) and fasting plasma glucose (FPG) target recommendations set in the ADA (11-14) and IDF (8) guidelines for T2DM adult outpatients with either healthy or few comorbid status.

This study was initiated to present and characterize treatment patterns of T2DM in the chronic care clinic of the study setting and, to estimate the proportion of patients who successfully have controlled both BP and FPG levels during their last visits of the study period. In addition, the factors associated with poor goal achievement in the pharmacotherapy of T2DM were determined. The study is deemed to contribute to the identification of appropriate areas of focus that would help in the achievement of target levels in BP and FPG management among T2DM patients.

\section{METHOD}

Study design and setting: An institution based cross sectional study was conducted in Federal Police Referral Hospital in Addis Ababa, Ethiopia, from $15^{\text {th }}$ October 2016 to $15^{\text {th }}$ January 2017. The hospital has a total of 300 beds and is engaged in providing both diagnostic and medical treatment services to closely 1900 in-patients and 22000 outpatients.

Source and study population: The source population of this study was all chronic patients who were attending to the outpatients of the hospital while the study population was the T2DM patients, and fulfilled the specified inclusion criteria.

Inclusion and exclusion criteria: The inclusion criteria for the study comprised patients who had uninterrupted follow-up to the clinic since at least one year back, those with complete medical history in their chart or database records, those who had their last visit BP and FPG level status measured, those who were aged above 18 years, and those who gave informed verbal consent to participate in the study. On the other hand, T2DM patients with treatment duration of less than a year, those patients who had not been measured for their last visit BP and FPG levels, those with

DOI: http://dx.doi.org/10.4314/ejhs.v28i4.12 
incomplete records about their last visit measurement (for patients who were either unable to recall or whose last visit records were unreadble), patients with incomplete medication or disease history either in the diabetes clinic or chronic care pharmacy database, and patients who did not give informed verbal consent were excluded from the study.

Sample size: The sample size was calculated by using single population proportion formula (15) and the prevalence of diabetes mellitus among the members of Federal Police Commission who resided in Addis Ababa, the capital of Ethiopia (6).

After adjusting the above figure using a finite population correction formula (15) to compute the minimum number of patients with T2DM and those who were on follow-up to the chronic care clinic, and adding a $10 \%$ non-response rate or incomplete records, the final sample size required for the study was 414 .

Sampling technique: A Systematic random sampling technique was employed in selecting the study participants. Initially, the total number of the study participants was identified based on their chronic care clinic visit and medication refill appointment dates in the chronic care pharmacy unit database. As refills were done every three months, the sampling interval was determined by dividing the total number of persons with T2DM to the required sample size. Accordingly, a random serial number between 0 and the sampling interval was selected, and selection was continued till the end based on the patient's appointment date to refill the medications.

\section{Data collection procedure and quality} assurance: Data was collected using semistructured interview of the study participants by a trained pharmacist. Interview was scheduled based on the participants' refill date to the chronic care pharmacy unit. After obtaining their informed consent, participants were briefed about the purpose of the study, and invited whether they would want to participate in the study. They were also assured to withdraw from the interview at any moment if they were uncomfortable. Sociodemographic characteristics, disease history and adherence issues were recorded by interviewing the participants. Last visit outcome results were taken from medication charts based on the medication record numbers (MRNs). Classes of drugs prescribed, type of therapy and number of drugs were identified from prescription papers and database records.

For ensuring consistency, clarity and data quality, the interview was conducted in Amharic (the country's official language which all participants speak). The data collector was trained for two days on the relevance of the study, data collection techniques, informed consent and confidentiality of the data collected. Prior to the start of the data collection, a pilot of 30 patients' medication records obtained from the chronic care clinic was evaluated against the required variables in the study. Completeness of data was checked every day by principal investigators (PIs).

\section{Operational definitions}

Blood pressure control: Blood pressure was measured based on either the systolic or diastolic pressure records of the participant. BP was assumed controlled if the systolic BP was between 110 and $139 \mathrm{mmHg}$ and diastolic BP was between 70 and $89 \mathrm{mmHg}$. If either target was missed, it was considered that blood pressure was not controlled.

Fasting plasma glucose control: Also used as glycemic control was considered between 100 and $130 \mathrm{mg} / \mathrm{dl}$ for this evaluation.

Dietary adherence: This was measured based on vegetable, fiber, salt, fat and alcohol intake levels. Dietary adherence was considered good if the participant reported to taking at least 2 servings of vegetables/fruits for 3 or more days of the week, whole grains, fiber or fish at least 2 servings for 3 or more days of the week, small amount of fat or sugar, less than $2.3 \mathrm{~g}$ salt $(<1$ Tea Spoon Full (TSF)) intake per day, and less than $600 \mathrm{ml}$ alcoholic intake per day.

Exercise adherence: This was considered active if the participant reported doing exercise for at least 30 minutes in 4 or more days of the week.

Medication adherence: Medication adherence was measured based on a participant's reported daily missed doses of the prescribed anti-diabetic medications. If the participant had not missed

DOI: http://dx.doi.org/10.4314/ejhs.v28i4.12 
more than 80 percent of the doses in a month, it was assumed to have a good adherence.

Terminology: the terms 'T2DM /patients' and 'study/ participants' have been used interchangeably in this article.

Ethical approval and consent: The study was approved by the School of Pharmacy Research and Ethics Committee, College of Health Sciences, Addis Ababa University. Before the start of the actual data collection, permission was obtained from Federal Police Commission Health Service Directorate. The study was conducted with an informed verbal consent acquired from each participant, and the data collection was conducted confidentially. Personal identifiers such as medical record number (MRN), name, address and telephone number were not included in the personal information interview.

Data analysis: The collected data was coded and checked manually for completeness; it was entered into Statistical Package for Social Sciences (SPSS) version 20 and cleaned before analysis. Frequency distributions and percentage tables were used to present socio-demographic variables and participants' characteristics. A multivariable logistic regression was performed to show possible associations between the dependent variables (BP, FPG and simultaneous BP and FPG targets) and independent (age, gender, and marital status, comorbidity, type of therapy, dietary adherence, medication adherence and physical exercise) variables. Statistical significance was set at $\mathrm{p}<0.05$. Target achievement of each outcome variable was tested individually and in combination. Because national diabetes guideline was not available in Ethiopia, target levels used in this study were set based on recommendations by the ADA (11-14) and IDF (8).

\section{RESULTS}

Characteristics of study participants: Out of a total of 414 participants who fulfilled the inclusion criteria, 361 were interviewed successfully, and considered for further analysis which made a response rate of $87.2 \%$. The mean age of the respondents was 54.8 years with standard deviation (SD) of \pm 11.9 years. Duration of treatment ranged between 1 and 31 years with mean duration of 6.7 years. Systolic blood pressure ranged between 100 and $200 \mathrm{mmHg}$ with mean of 131.6 and SD of $\pm 16.7 \mathrm{mmHg}$. Diastolic blood pressure was reported between 60 and 120 $\mathrm{mmHg}$ with mean of 84.7 and SD of $\pm 9.0 \mathrm{mmHg}$. The mean (SD) of fasting plasma glucose level was $154( \pm 51) \mathrm{mg} / \mathrm{dl}$ ranging from 70 to 385 $\mathrm{mg} / \mathrm{dl}$

More than half $(56.5 \%)$ of the participants were males, while greater than $40 \%$ of the respondents were in the age group of below 45 years. Nearly two-third (65.1\%) of the participants in this study were members of the military while almost all $(98.3 \%)$ were married. About $209(58 \%)$ of the participants had at least one type of comorbidity. The most frequent comorbidity was hypertension reported by $145(40.2 \%)$ of the participants followed by dyslipidemia (30.5\%), cardiac abnormalities $(2.2 \%)$, peripheral neuropathy $(1.9 \%)$, dyspepsia $(1.9 \%)$ and retroviral infection $(1.4 \%)$.

One hundred seventy-seven (49\%) participants reported that they were taking oral combination therapy followed by those who reported Insulin and oral combination therapy $(21.9 \%)$, and oral mono therapy (15\%) (Table1). The oral combination therapies were metformin with glibenclamide. Metformin was also combined with long acting insulin suspension. The majority (94\%) of the patients placed on the monotherapy regimen took metformin while the rest took either glibenclamide or glimepiride. The patients on the insulin combination therapy took both intermediate acting (NPH) and short acting (regular insulin) regimens or a mixed formulation of both (mixtard).

DOI: http://dx.doi.org/10.4314/ejhs.v28i4.12 
Table 1: Characteristics of T2DM patients attending the chronic care clinic of Federal Police Referral Hospital, 2017 ( $\mathrm{n}=361)$

\begin{tabular}{llll}
\hline Characterstics & Category & Frequency & Percent \\
\hline Age & $\leq 45$ Years & 150 & 41.5 \\
& $46-60$ Years & 127 & 35.2 \\
& $>60$ Years & 84 & 23.3 \\
Gender & Female & & 43.5 \\
& Male & 157 & 56.5 \\
Military status & Military & 204 & 65.1 \\
& Non-military & 235 & 34.9 \\
Marital status & Married & 126 & 98.3 \\
& Unmarried & 355 & 1.7 \\
Comorbidity & No & 6 & 42.1 \\
& Yes & 152 & 57.9 \\
Type of therapy & Oral mono therapy & 209 & 15.0 \\
& Oral combination therapy & 177 & 49.0 \\
& Insulin mono/combination & 51 & 14.1 \\
& therapy & & 21.9 \\
\hline
\end{tabular}

Factors associated with blood pressure control: Overall, target BP level (both systolic and diastolic) was achieved in 206(57.1\%) of the study participants, whereas the BP level reported by the rest of the participants was out of the recommended range. However, the proportion of hypertensive diabetics who attained the recommended BP target was $19.4 \%(n=40)$.

The odds of achieving BP targets were analyzed in association to selected univariate and multivariate characteristics of T2DM patients. Accordingly, male gender (AOR: 0.26, 95\% CI: $0.13-0.53$ ), being non-military (AOR: $0.35,95 \%$ CI: $0.17-0.74$ ), presence of comorbidity (AOR: $0.16,95 \% \mathrm{CI}: 0.09-0.27$ ), and being in the regimen of oral combination therapy (AOR: $0.42,95 \% \mathrm{CI}$ : $0.20-0.88$ ) showed negative associations with $\mathrm{BP}$ target achievement (Table 2).
Factors associated with fasting plasma glucose control: Out of the 361 participants who were checked about their current FPG level, only 142 $(39.3 \%)$ was found to be $<130 \mathrm{mg} / \mathrm{dl}$ which was regarded as good glycemic control. Out of the participant characteristics tested for potential association with target control of FPG, being nonmilitary in status (AOR: 0.73; 95\% CI: 0.38-0.82), taking oral combination therapy (AOR: 0.37, 95\%CI: $0.18-0.76)$ and insulin +oral combination therapy (AOR: 0.33; 95\% CI: 0.14-0.77) showed statistically significant negative associations. On the other hand, presence of comorbidity (AOR: 1.8 ; 95\% CI: 1.07-3.04) and good dietary adherence (AOR: 3.46; 95\% CI: 2.04-5.87) showed high likelihood of FPG target achievement among the patients (Table 3). 
Table 2: Multivariate association of selected characteristics with BP control among T2DM patients in Federal Police Referral Hospital, Addis Ababa, 2017 (n=361)

\begin{tabular}{|c|c|c|c|c|c|}
\hline \multirow[t]{2}{*}{ Characteristics } & & \multicolumn{2}{|c|}{ Target BP Control } & \multirow[t]{2}{*}{ COR (95\%CI) } & \multirow[t]{2}{*}{ AOR $(95 \% C I)$} \\
\hline & & Yes $(\%)$ & No (\%) & & \\
\hline \multirow[t]{3}{*}{ Age (Years) } & $\leq 45$ & $95(63.3)$ & $55(36.7)$ & 1.00 & 1.00 \\
\hline & $46-60$ & $71(55.9)$ & $56(44.1)$ & $0.73(0.45-1.20)$ & $0.66(0.37-1.18)$ \\
\hline & $>60$ & $40(47.6)$ & $44(52.4)$ & $0.53(0.31-0.91)$ & $0.74(0.36-1.52)$ \\
\hline \multirow[t]{2}{*}{ Gender } & Female & $108(68.8)$ & $49(31.2)$ & 1.00 & 1.00 \\
\hline & Male & $98(48.0)$ & $106(52.0)$ & $0.42(0.27-0.65)$ & $0.26(0.13-0.53)^{*}$ \\
\hline \multirow[t]{2}{*}{ Military status } & Military & $130(55.3)$ & $105(44.7)$ & 1.00 & 1.00 \\
\hline & Non-military & $76(60.3)$ & $50(39.7)$ & $1.23(0.79-1.91)$ & $0.35(0.17-0.74)^{*}$ \\
\hline \multirow[t]{2}{*}{ Comorbidity } & No & $122(80.3)$ & $30(19.7)$ & 1.00 & 1.00 \\
\hline & Yes & $84(40.2)$ & $125(59.8)$ & $0.17(0.10-0.27)$ & $0.16(0.09-0.27)^{*}$ \\
\hline Treatment & $\leq 5$ & $131(60.4)$ & $86(39.6)$ & 1.00 & 1.00 \\
\hline \multirow[t]{2}{*}{ Duration(Years) } & $6-10$ & $43(52.4)$ & $39(47.6)$ & $0.72(0.43-1.23)$ & $0.82(0.43-1.56)$ \\
\hline & $\geq 11$ & $32(51.6)$ & $30(48.4)$ & $0.70(0.40-1.24)$ & $0.83(0.37-1.83)$ \\
\hline \multirow[t]{4}{*}{ Type of therapy } & Oral mono therapy & $35(64.8)$ & $19(35.2)$ & 1.00 & 1.00 \\
\hline & $\begin{array}{l}\text { Oral combination } \\
\text { therapy }\end{array}$ & $94(53.1)$ & $83(46.9)$ & $0.62(0.33-1.16)$ & $0.42(0.20-0.88)^{*}$ \\
\hline & $\begin{array}{l}\text { Insulin mono/combination } \\
\text { therapy }\end{array}$ & $30(58.8)$ & $21(41.2)$ & $0.78(0.35-1.71)$ & $0.59(0.23-1.51)$ \\
\hline & $\begin{array}{l}\text { Insulin +oral } \\
\text { combination therapy }\end{array}$ & $47(59.5)$ & $32(40.5)$ & $0.80(0.40-1.63)$ & $1.16(0.50-2.68)$ \\
\hline \multirow{2}{*}{$\begin{array}{l}\text { Dietary } \\
\text { adherence }\end{array}$} & Poor & $84(50.3)$ & $83(49.7)$ & 1.00 & 1.00 \\
\hline & Good & $122(62.9)$ & $72(37.1)$ & $1.67(1.10-2.60)$ & $1.63(0.96-2.75)$ \\
\hline \multirow{2}{*}{$\begin{array}{l}\text { Physical } \\
\text { exercise }\end{array}$} & Inactive & $22(48.9)$ & $23(51.1)$ & 1.00 & 1.00 \\
\hline & Active & $184(58.2)$ & $132(41.8)$ & $46(0.78-2.73)$ & $1.00(0.47-2.13)$ \\
\hline \multirow{2}{*}{$\begin{array}{l}\text { Medication } \\
\text { Adherence }\end{array}$} & Poor & $19(41.3)$ & $27(58.7)$ & 1.00 & 1.00 \\
\hline & Good & $187(59.4)$ & $128(40.6)$ & $2.10(1.12-3.90)$ & $1.38(0.62-3.09)$ \\
\hline
\end{tabular}

*statistically significant

DOI: http://dx.doi.org/10.4314/ejhs.v28i4.12 
Table 3: Multivariate association of selected characteristics with FPG control among T2DM patients in Federal Police Referral Hospital, Addis Ababa, 2017 (n=361).

\begin{tabular}{|c|c|c|c|c|c|}
\hline \multirow{2}{*}{\multicolumn{2}{|c|}{ Characteristics }} & \multicolumn{2}{|c|}{ Target FPG Control } & \multirow[t]{2}{*}{ COR (95\%CI) } & \multirow[t]{2}{*}{$\overline{A O R}(95 \% C I)$} \\
\hline & & Yes (\%) & No $(\%)$ & & \\
\hline \multirow[t]{3}{*}{ Age (Years) } & $\leq 45$ & $60(40.0)$ & $90(60.0)$ & 1.00 & 1.00 \\
\hline & $46-60$ & $43(33.9)$ & $84(66.1)$ & $0.77(0.47-1.26)$ & $0.59(0.32-1.06)$ \\
\hline & $>60$ & $39(46.4)$ & $45(53.6)$ & $1.30(0.76-2.23)$ & $0.74(0.37-1.50)$ \\
\hline \multirow[t]{2}{*}{ Gender } & Female & $57(36.3)$ & $100(63.7)$ & 1.00 & 1.00 \\
\hline & Male & $85(41.7)$ & $119(58.3)$ & $1.25(0.82-1.92)$ & $0.73(0.38-1.38)$ \\
\hline \multirow[t]{2}{*}{ Military status } & Military & $105(44.7)$ & $130(55.3)$ & 1.00 & 1.00 \\
\hline & Non-military & $37(29.4)$ & $89(70.6)$ & $0.52(0.32-0.82)^{*}$ & $0.42(0.21-0.82)^{*}$ \\
\hline \multirow[t]{2}{*}{ Comorbidity } & No & $51(33.6)$ & $101(66.4)$ & 1.00 & 1.00 \\
\hline & Yes & $91(43.5)$ & $118(56.5)$ & $1.53(0.99-2.36)$ & $1.80(1.07-3.04)^{*}$ \\
\hline \multirow{3}{*}{$\begin{array}{l}\text { Treatment } \\
\text { duration (Years) }\end{array}$} & $\leq 5$ & $82(37.8)$ & $135(62.2)$ & 1.00 & 1.00 \\
\hline & $6-10$ & $29(35.4)$ & $53(64.6)$ & $0.90(0.53-1.53)$ & $1.04(0.54-1.98)$ \\
\hline & $\geq 11$ & $31(50.0)$ & $31(50.0)$ & $1.65(0.93-2.91)$ & $1.84(0.84-4.03)$ \\
\hline \multirow[t]{5}{*}{ Type of therapy } & Oral mono therapy & $28(51.9)$ & $26(48.1)$ & 1.00 & 1.00 \\
\hline & $\begin{array}{l}\text { Oral combination } \\
\text { therapy }\end{array}$ & $59(33.3)$ & $118(66.7)$ & $0.46(0.25-0.86)^{*}$ & $0.37(0.18-0.76)^{*}$ \\
\hline & Insulin & $28(54.9)$ & $23(45.1)$ & $1.13(0.23-2.44)$ & $0.70(0.29-1.70)$ \\
\hline & $\begin{array}{l}\text { mono/combination } \\
\text { therapy }\end{array}$ & & & & \\
\hline & $\begin{array}{l}\text { Insulin +oral } \\
\text { combination therapy }\end{array}$ & $27(34.2)$ & $52(65.8)$ & $0.48(0.24-0.98)^{*}$ & $0.33(0.14-0.77)^{*}$ \\
\hline \multirow{2}{*}{$\begin{array}{l}\text { Dietary } \\
\text { adherence }\end{array}$} & Poor & $39(23.4)$ & $128(76.6)$ & 1.00 & 1.00 \\
\hline & Good & $103(53.1)$ & $91(46.9)$ & $3.72(2.35-5.86)^{*}$ & $3.46(2.04-5.87)^{*}$ \\
\hline \multirow{2}{*}{$\begin{array}{l}\text { Physical } \\
\text { exercise }\end{array}$} & Inactive & $10(22.2)$ & $35(77.8)$ & 1.00 & 1.00 \\
\hline & Active & $132(41.8)$ & $184(58.2)$ & $2.51(1.20-5.25)^{*}$ & $1.82(0.80-4.11)$ \\
\hline \multirow{2}{*}{$\begin{array}{l}\text { Medication } \\
\text { adherence }\end{array}$} & Poor & $8(17.4)$ & $38(82.6)$ & 1.00 & 1.00 \\
\hline & Good & $134(42.5)$ & $181(57.5)$ & $3.52(1.59-7.78) *$ & $2.08(0.82-5.25$ \\
\hline
\end{tabular}

*statistically significant

Factors associated with both blood pressure and fasting plasma glucose control: Overall, simultaneous BP and FPG level of only the $87(24.1 \%)$ participants was found within the recommended range. The variables which showed statistically significant associations with control of the outcome variable were male gender (AOR:0.31; 95\% CI: 0.15-0.66), being non- military in status (AOR: 0.25; 95\% CI: 0.11-0.55), taking oral combination therapy (AOR: $0.18 ; 95 \%$ CI: 0.08-0.40), taking insulin mono or combination therapy (AOR: 0.29 ; 95\% CI: 0.110.77), taking insulin+oral combination therapy (AOR: $0.32 ; 95 \%$ CI: 0.13-0.81), and good dietary adherence (AOR: 5.68; 95\% CI; 2.8511.35) (Table 4). 
Table 4: Multivariate association of selected characteristics with both BP and FPG control among T2DM patients in Federal Police Referral Hospital, Addis Ababa, 2017 ( $\mathrm{n}=361)$.

\begin{tabular}{|c|c|c|c|c|c|}
\hline \multirow{2}{*}{\multicolumn{2}{|c|}{ Characteristics }} & \multirow{2}{*}{\multicolumn{2}{|c|}{ Target BP and FPG }} & COR $(95 \% C I)$ & AOR (95\%CI) \\
\hline & & & & & \\
\hline \multirow[t]{3}{*}{ Age (Years) } & $\leq 45$ & $42(28.8)$ & $108(72.0)$ & 1.00 & 1.00 \\
\hline & $46-60$ & $28(22.0)$ & $99(78.0)$ & $0.73(0.42-1.26)$ & $0.53(0.26-1.05)$ \\
\hline & $>60$ & $17(20.2)$ & $67(79.8)$ & $0.65(0.34-1.24)$ & $0.52(0.22-1.22)$ \\
\hline \multirow[t]{2}{*}{ Gender } & Female & $46(29.3)$ & $111(70.7)$ & 1.00 & 1.00 \\
\hline & Male & $41(20.1)$ & $163(79.9)$ & $0.61(0.37-0.99)^{*}$ & $0.31(0.15-0.66)^{*}$ \\
\hline \multirow[t]{2}{*}{ Military status } & Military & $61(26.0)$ & $174(74.0)$ & 1.00 & 1.00 \\
\hline & Non-military & $26(20.6)$ & $100(79.4)$ & $0.74(0.44-1.25)$ & $0.25(0.11-0.55) *$ \\
\hline \multirow[t]{2}{*}{ Comorbidity } & No & $48(31.6)$ & $104(68.4)$ & 1.00 & 1.00 \\
\hline & Yes & $39(18.7)$ & $170(81.3)$ & $0.50(0.31-0.81)^{*}$ & $0.59(0.32-1.09)$ \\
\hline \multirow{3}{*}{$\begin{array}{l}\text { Treatment } \\
\text { duration (Years) }\end{array}$} & $\leq 5$ & $60(27.6)$ & $157(72.4)$ & 1.00 & 1.00 \\
\hline & $6-10$ & $13(15.9)$ & $69(84.1)$ & $0.49(0.25-0.96)^{*}$ & $0.55(0.24-1.25)$ \\
\hline & $\geq 11$ & $14(22.6)$ & 48(77.4) & $0.76(0.39-1.49)$ & $0.96(0.38-2.42)$ \\
\hline \multirow[t]{4}{*}{ Type of therapy } & Oral mono therapy & $24(44.4)$ & $30(55.6)$ & 1.00 & 1.00 \\
\hline & $\begin{array}{l}\text { Oral combination } \\
\text { therapy }\end{array}$ & $33(18.6)$ & $144(81.4)$ & $0.29(0.15-0.55)^{*}$ & $0.18(0.08-0.40)^{*}$ \\
\hline & $\begin{array}{l}\text { Insulin } \\
\text { mono/combination } \\
\text { therapy }\end{array}$ & $16(31.4)$ & $35(68.6)$ & $0.57(0.26-1.27)$ & $0.29(0.11-0.77)^{*}$ \\
\hline & $\begin{array}{l}\text { Insulin +oral } \\
\text { Combination } \\
\text { therapy }\end{array}$ & $14(17.7)$ & $65(82.3)$ & $0.27(0.12-0.59)^{*}$ & $0.32(0.13-0.81)^{*}$ \\
\hline \multirow{2}{*}{$\begin{array}{l}\text { Dietary } \\
\text { adherence }\end{array}$} & Poor & $16(9.6)$ & 151(90.4) & 1.00 & 1.00 \\
\hline & Good & $71(36.6)$ & $123(63.4)$ & $5.45(3.01-9.85)^{*}$ & $5.68(2.85-11.35)^{*}$ \\
\hline \multirow{2}{*}{$\begin{array}{l}\text { Physical } \\
\text { exercise }\end{array}$} & Inactive & $6(13.3)$ & $39(86.7)$ & 1.00 & 1.00 \\
\hline & Active & $81(25.6)$ & $235(74.4)$ & $2.24(0.92-5.49)$ & $1.32(0.46-3.82)$ \\
\hline \multirow{2}{*}{$\begin{array}{l}\text { Medication } \\
\text { adherence }\end{array}$} & Poor & $4(8.7)$ & $42(91.3)$ & 1.00 & 1.00 \\
\hline & Good & $83(26.3)$ & $232(73.7)$ & $3.76(1.31-10.80) *$ & $0.67(0.19-2.38)$ \\
\hline
\end{tabular}

*statistically significant

\section{DISCUSSION}

$\mathrm{DM}$ is a complex, chronic illness that requires continuous care targeting for reduction of multiple risk factors beyond glycemic control. Ongoing patient self-management education and support are critical to preventing acute complications and reducing their long-term progress of the disease (11-14). Particularly, achievement of hypertension, glycemic and lipid target levels

DOI: http://dx.doi.org/10.4314/ejhs.v28i4.12 
among T2DM patients is reported to result in halting such complications and improve quality of life $(10,16-18)$. In this study, a higher figure of BP control (both systolic and diastolic) was obtained.This might be attributed to the fact that majority of the participants were not hypertensive. However, the level of attaining target BP was found to vary significantly among hypertensive and non-hypertensive subgroups. The proportion of hypertensive diabetics who achieved target BP level in this study was in line with findings from studies across developed nations which reported that only less than one-third of hypertensive diabetics achieved their target BP level $(19,20)$. However, a higher figure(32.2\%) was reported among a similar group of Korean patients to have reached their treatment goal (21). Even though the figure in our study appears to be lower $(19.4 \%)$, the proportion of hypertensive diabetics is also relatively smaller $(40.2 \%$ vs. $45 \%)$, whereas the total number of participants in the same study is higher $(n=361)$ compared to the study in Korea $(n=200)$. Nonetheless, this study indicates that the association between DM and hypertension is on the rise which might have led to the lower level BP target. Studies from Sweden and Spain have shown that diabetes and hypertension have additive interaction which, in turn, is linked to elevated renin-angiotensin-aldosterone system activity, hyper-insulinemia associated to increased renal reabsorption of sodium, and increased sympathetic tone $(22,23)$.

In the present study, $142(39.3 \%)$ of the participants attained FPG of $130 \mathrm{mg} / \mathrm{dl}$ or less which was classified as good glycemic level. Smaller figures of glycemic control level had been reported from Malaysia $(24,25)$ and Jordan (26). Reasons for the difference might include high proportion of patients with comorbidity and diets high in carbohydrates (24) and lack of physical activity in the respective countries $(24,25)$ compared to ours. Conversely, a higher figure of good glycemic control level was documented by studies in Korea (21) and Japan (27). This could be because of higher literacy rate and availability of better treatment options in these countries.

Simultaneous achievement of both BP and FPG, in the present study, was a remarkable challenge where only $24.1 \%$ of the participants were in the target range. However, even smaller figures of $14.8 \%, 11.2 \%$ and $18.8 \%$ were reported in Korea (21), Japan (27) and US (28) respectively. Even though more advanced management options are available in the developed nations, the fact that the present study considered only BP and FPG targets unlike the other studies (which in addition included lipid control) might have overestimated the figure. Variation in presence of cardiovascular diseases and other complications, diabetes selfmanagement approaches and genetic (racial) factors might have brought about the observed difference.

Male gender was found to contribute to decreased glycemic control level in this study. This might be linked to the presence of various comorbid conditions among two-third of the male participants compared to the same case in females (46\%). Many experimental and clinical studies have also evidenced that men are hemodynamically older than age matched premenauposal women (29-31). Similarly, based on the two longitudinal studies; the FRAMINGHAM HEART STUDY (32) and the INTERHEART (33) studies, the overall median age for evident CVD is 10 years lower in men than in their female counterparts. The progress of many CVDs leads to more advanced complication and vascular dysfunction which, in turn, is related with visceral adiposity, insulin resistance (IR) and change in levels of various circulating factors (34). This variation is explained by many studies which have found that female hormone; especially, estrogen has a notable role in promoting cardiovascular protection (35-37), regulation of energy balance, fat distribution and insulin sensitivity (38). This also may imply that male gender and comorbidity had interactive effects in this association despite administration of anti-diabetic medications in both groups.

Compared to oral mono-therapy, people who take any of the oral combination, insulin mono/combination or insulin+oral combination therapy were found to poorly control their BP and FPG targets. This may be attributed to multiple factors such as poor insulin self-administration (though the majority reported to have good medication adherence), presence of drug-drug or 
drug-food interaction and insulin stability while stored at home.

This study did not include cholesterol measures though this variable often plays a considerable role in glycemic control in addition to BP and FPG, as patient records were incomplete for the point of evaluation. Similarly, FPG was used an outcome variable since Hbalc tests were not available in the hospital. The study, however, has tried to present an informative picture of T2DM treatment pattern and associated factors with achievement of BP and FPG targets and, may serve as a baseline for future studies. The proportion of participants with T2DM and those who achieved BP and FPG targets was suboptimal in the present study. Similarly, simultaneous achievement of both BP and FPG target levels was lacking in the three-fourth of the study participants. This implies that meeting targets in T2DM treatment needs a considerable attention though burden of the disease appears to be at its earlier stage of growth in the country. Gender, military status, comorbidity, type of therapy and dietary adherence showed statistically significant associations with BP and FPG level control. As T2DM is a complex effect of multiple risk factors, a comprehensive approach that involves targeted education on self-management strategies, individualized treatment plans and continuous evaluation of treatment outcomes should be practiced. Further studies with better design and scope are also warranted to determine the magnitude of the problem, in the country, in a more precise way.

\section{ACKNOWLEDGEMENTS}

We would like to thank the staff members of the Chronic Care Clinic and Chronic Care Pharmacy units of Federal Police Referral Hospital for their unreserved support during the conduct of this study. We also forward our deepest gratitude to patients with chronic illnesses who gave informed consent to participate in this study.

\section{REFERENCES}

1. NCD Risk Factor Collaboration (NCD-RisC). Worldwide trends in diabetes since 1980: a pooled analysis of 751 population-based studies with 16 million participants. Lancet. 2016,387 (10027): 1513-1530. http://dx.doi.org/10.1016/S01406736(16)00618-8.

2. World Health Organization. Global Burden of Diabetes. Switzerland, Geneva. 2016. Available from: http://www. apps.who.int/iris/bitstream/10665/.../1/WHO_ NMH_NVI_16.3_eng.pdf /accessed 10 December 2016/

3. ACIPH \& MIRT. Preliminary Results survey of non-communicable diseases among bank employees and teachers in Addis Ababa. http://www.addiscontinental.edu.et/files/aciph communicable_disease.pdf (2010). Accessed 23 Nov 2014.

4. Megerssa Y, Gebre M, Birru S, Goshu A, Tesfaye D. Prevalence of undiagnosed Diabetes Mellitus and its factors in selected Institutions at Bishoftu Town, East Shoa, Ethiopia. J Diabetes Metab. 2013;12:21556156.

5. Belayneh A, Teklie H, Tadesse M, Defar A, Getachew T, Amenu K, et al. Pattern and Trend of Medical Admissions of Patients of Chronic Non-Communicable Diseases in Selected Hospitals in Addis Ababa, Ethiopia. Am Scientific Res $J$ Eng, TechnolSci(ASRJETS). 2015; 13(1):33-48.

6. Tesfaye T, Shikur B, Shimels T, Firdu N. Prevalence and factors associated with diabetes mellitus and impaired fasting glucose level among members of federal police commission residing in Addis Ababa, Ethiopia. BMC EndocrDisord. 2016;28(16) (1):68

7. Lester FT, Tsega E. The pattern of adult medical admission in Addis Ababa, Ethiopia. East Afr Med J. 1976;53:620-634.

8. International Diabetes Federation. IDF Diabetes Atlas, 6th ed. Brusseles, Belgium: International Diabetes Federation, 2014. http://www.idf.org/diabetesatlas/update-2014. Accessed 23 Nov 2016

9. The Diabetes Control and Complications Trial Research Group: The effect of intensive treatment of diabetes on the development and

DOI: http://dx.doi.org/10.4314/ejhs.v28i4.12 
progression of long-term complications in insulin-dependent diabetes mellitus. $N$ Engl $J$ Med. 1993; 329(14):977-986.

10. UKPDS: Intensive blood-glucose control with sulphonylureas or insulin compared with conventional treatment and risk of complications in patients with type 2 diabetes (UKPDS 33). Lancet. 1998;352(9131):837853.

11. American Diabetes Association. Standards of medical care in diabetes-2011. Diabetes Care. 2011;34 (Suppl. 1):S11-61.

12. American Diabetes Association. Standards of medical care in diabetes-2016. Diabetes Care. 2016;39(suppl1):S1-S106

13. American Diabetes Association. Glycemic targets. Sec. 6. In Standards of Medical Care in Diabetesd 2015. Diabetes Care. 2015;38(Suppl. 1):S33-S40

14. American Diabetes Association. Standards of medical care in diabetes-2014. Diabetes Care. 2014; 37(suppl1):S14-S80.

15. Berenson, ML, Levine DM, and Szabat K. Estimation and Sample Size Determination for Finite Populations. Basic Business Statistics: Global Edition. 2013. Available on: https://www.alnap.org/help-library/estimationand-sample-size-determination-for-finitepopulations-basic-business. Accessed on 22 Jan 2018.

16. Patel A, MacMahon S, Chalmers J, Neal B, Billot L, Woodward M, et al. Intensive blood glucose control and vascular outcomes in patients with type 2 diabetes.ADVANCE Collaborative Group. $N$ Engl $J$ Med. 2008;358:2560-72.

17. Gerstein HC, Miller ME, Byington RP, Goff DC Jr, Bigger JT, Buse JB, et al. Effects of intensive glucose lowering in type 2 diabetes. Action to Control Cardiovascular Risk in Diabetes Study Group. $N$ Engl $J$ Med. 2008;358:2545-59.

18. Park SW, Kim DJ, Min KW, Baik SH, Choi KM, Park IB, et al. Current status of diabetes management in Korea using national health insurance database. J Korean Diabetes Assoc. 2007;31: 362-7.

19. Mancia G, Laurent S, Agabiti-Rosei E, Ambrosioni E, Burnier M, Caulfield MJ,
Cifkova R, Clement D, Coca A, Dominiczak A, et al: Reappraisal of European guidelines on hypertension management: a European Society of Hypertension Task Force document. Blood Press. 2009; 18(6):308-347.

20. Matthaei S, Bierwirth R, Fritsche A, Gallwitz B, Häring H-U, Joost H-G, Kellerer M, Kloos C, Kunt T, Nauck M, et al: Treatment of type2 diabetes mellitus. Diabetologie. 2011, 6(Suppl. 2):S131-S136.

21. Kang AY, Park SK, Park SY, Lee HJ, Han Y, Lee SR, et al. Therapeutic Target Achievement in Type 2 Diabetic Patients after Hyperglycemia, Hypertension, Dyslipidemia Management. Diabetes Metab J. 2011; 35:264-272.

22. Nilsson PM, Cederholm J, Zethelius BR, Eliasson BR, Eeg-Olofsson K, GudbjRnsdottir S. Trends in blood pressure control in patients with type 2 diabetes: data from the Swedish National Diabetes Register (NDR). Blood Press. 2011; 20:348-354.

23. Redon J, Cifkova R, Laurent S, Nilsson P, Narkiewicz K, Erdine S, Mancia G. Mechanisms of hypertension in the cardiometabolic syndrome. J Hypertens. 2009; 27: 441-451 [PMID:19262221 DOI: 10.1097/HJH.0b013e32831e13e5]

24. Ahmad NS, Islahudin F, Paraidathathu T.Factors associated with good glycemic control among patients with type 2 diabetes mellitus.J Diabetes Invest. 2014; 5: 563-569.

25. Ismail IS, Nazaimoon WMW, Wan Mohamad WB, et al. Sociodemographic determinants of glycemic control in young diabetic patients in peninsular Malaysia. Diabetes Res Clin Pract. 2000; 47: 57-69.

26. Khattaba M, Khaderb YS, Al-Khawaldehd A, et al. Factors associated with poor glycemic control among patients with Type 2 diabetes. $J$ Diabetes Complications. 2010; 24: 84-89.

27. Hu H, Hori A, Nishiura C, Sasaki N, Okazaki $\mathrm{H}$, Nakagawa $\mathrm{T}$ et al. Hbalc, blood pressure, and lipid control in people with diabetes: Japan epidemiology collaboration on occupational health study. PLOS ONE. 2016: 11(7). Doi:10.1371/journal.pone.0159071.

28. Casagrande SS, Fradkin JE, Saydah SH, Rust KF, Cowie CC. The Prevalence of Meeting

DOI: http://dx.doi.org/10.4314/ejhs.v28i4.12 
A1C, Blood Pressure, and LDL Goals among People with Diabetes, 1988-2010. Diabetes Care. 2013; 36:2271-2279.

29. F. H. Messerli, G. E. Garavaglia, R. E. Schmieder et al., "Disparate cardiovascular findings in men and women with essential hypertension," Annals of Internal Medicine. 1987;107(2): 158-161.

30. C. N. BaireyMerz, L. J. Shaw, S. E. Reis et al., "Insights from the NHLBI-sponsored women's ischemia syndrome evaluation (WISE) study. Part II: gender differences in presentation, diagnosis, and outcome with regard to genderbased pathophysiology of atherosclerosis and macrovascular and microvascular coronary disease".Journal of the American College of Cardiology.2006; 47(3);S21-S29.

31. L. J. Shaw, C. N. BaireyMerz, C. J. Pepine et al., "Insights from the NHLBI-sponsored women's ischemia syndrome evaluation (WISE) study. Part I: gender differences in traditional and novel risk factors, symptom evaluation, and gender-optimized diagnostic strategies".Journal of the American College of Cardiology.2006; 47(3); S4-S20.

32. M. J. Pencina, R. B. D’Agostino Sr., M. G. Larson, J. M. Massaro, and R. S. Vasan, "Predicting the 30-year risk of cardiovascular disease: the Framingham heart study" .Circulation.2009;119(24):3078-3084.
33. S. S. Anand, S. Islam, A. Rosengren et al., "Risk factors for myocardial infarction in women and men: insights from the INTERHEART study". European Heart Journal. 2008;29(7): 932-940.

34. Ahmed I, Goldstein BJ. Cardiovascular risk in the spectrum of type 2 diabetes mellitus. $M t$ Sinai J Med. 2006; 73: 759-768.

35. V. M.Miller and S. P. Duckles, "Vascular actions of estrogens: functional implications".Pharmacological Reviews.2008;60(2) :210-241.

36. J. F. Couse, J. Lindzey, K. Grandien, J. A. Gustafsson, and K. S. Korach, "Tissue distribution and quantitative analysis of estrogen receptor- $\alpha$ (ER $\alpha)$ and estrogen receptor- $\beta$ (ER $\beta)$ messenger ribonucleic acid in the wild-type and ER $\alpha$ - knockout mouse".Endocrinology.1997;138(11):46134621.

37. C. Y. Pau, K. Y. F. Pau, and H. G. Spies, "Putative estrogen receptor $\beta$ and $\alpha \mathrm{mRNA}$ expression in male and female rhesus macaques".Molecular and Cellular Endocrinology.1998; 146 (1-2) pp. 59-68.

38. M. H. Faulds, C. Zhao, K. Dahlman-Wright, and J. A. Gustafsson, "The diversity of sex steroid action: regulation of metabolism by estrogen signaling".Journal of Endocrinology. 2012; 212(1):3-12. 